\title{
The Research on the Bottleneck of Liaoning Equipment Manufacturing Industry Technology Upgrading
}

\author{
Zou Hua ${ }^{*}$, Sun Jinliang and Wang Shiqi \\ School of Management, Shenyang University of Technology, Shenyang 110870, China
}

\begin{abstract}
In this paper, aiming at the problems of backward overall technology, weak competitiveness, poor operation efficiency and low production and economic efficiency in Liaoning equipment manufacturing industry, we based on the theory of constrains and used the DEA model to research its technology upgrading input and output efficiency to find its bottleneck, and then analysis its cause, finally put forward the corresponding countermeasures and Suggestions.
\end{abstract}

Keywords: Bottleneck, equipment manufacturing industry, technology upgrading.

\section{INTRODUCTION}

Currently, the development of Liaoning equipment manufacturing industry has entered a historic and critical stage, on one hand, with the deepening of the degree of market opening in the province, Foreign companies continue to enter the equipment manufacturing industry, triggering technology spillovers and technology transfer, and this phenomenon prompted the production capacity of equipment manufacturing industry continuously. On the other hand, a phenomenon manifests as the overall backward technology, lack of core competitiveness, Poor economic benefit and Low-tech products, so the markets continue to be eroded by foreign equipment companies. The fact of backward overall technology and weak competitiveness of Liaoning equipment manufacturing industry shows that Liaoning equipment manufacturing industry technology upgrading is restricted by some factors. Constraints is ubiquitous, and the bottlenecks are the key constraints, so how to identify and break through its bottlenecks is the current problem that Liaoning Province must recognize and solve [1].

\section{THE ESTABLISHMENT OF EVALUATION INDEX SYSTEM}

Bottleneck refers to a single or a few key factors which will make the enterprises and industries lack of development potential in the process of the development and is the weakest link in the whole system. Obviously, The Identification of Bottlenecks is not only the basis and key to Bottleneck Management, but also determines the effective output of the system and overall effectiveness of enterprises.

\subsection{The Choice of Identification Method}

Bottleneck is the key limiting factor in the overall and the process of bottleneck identification should first find out the overall effectiveness, and then find a single or a few key factors that limit the overall effectiveness [2]. Topsis (Technique for order preference by similarity to ideal solution) is a common method of multi-objective decision analysis of limited program. Its basic idea is that based on the original data matrix normalized, identify the optimal solution and the worst scenario in the limited program, then calculate the distance between the optimal solution and the worst scenario of each evaluation object, access to the relative proximity of each evaluation object and the optimal solution as a basis for evaluating the pros and cons. Sensitivity analysis refers to uncertainty analysis techniques to study the impact of the change of certain actors on one or a set of key indicators from the perspective of quantitative analysis, and its essence is to explain the law of the impact on key indicators by the change of these factors each by the method of changing the values of the related variables one by one. Therefore, the article first selects Topsis to calculate the overall efficiency ranking and which grades overall effectiveness of ranking and rating of Liaoning Province, and then calculate the Sensitivity strength of each indicator by using sensitivity analysis, and compare with the higher rating, and finally identify the bottlenecks of Liaoning Equipment manufacturing industry technological upgrading [3].

\subsection{The Selection of Evaluation Indexes}

The selection of indexes directly affects the establishment of performance indicators system and evaluation result, so it is required to follow the principles of authenticity and streamline, hierarchy and logicality, scientificity and operability [4]. Through a qualitative and quantitative analysis of Equipment Manufacturing Industry Technology Upgrading by a large number of experts, the result shows that the indicators which have impact on equipment manufacturing technology upgrades include R \& D, fixed assets, new products, patents, etc. Thus, the evaluation index system as shown in Table $\mathbf{1}$ is built according to such indicators Table $\mathbf{1}$. 
Table 1. The evaluation index system of Liaoning equipment manufacturing technology upgrading.

\begin{tabular}{|c|c|}
\hline Indicator Variables & Indicator Name \\
\hline \hline X1 (person) & R\&D Personnel \\
\hline X2 (10000 yuan) & Expenditure on R\&D \\
\hline X3 (10000 yuan) & Equipment \\
\hline X4 (unit) & Institutions \\
\hline X5 (10000 yuan) & Sales Revenue of New Products \\
\hline X6 (pierce) & Inventions In Force \\
\hline X7 (item) & New Products \\
\hline X8 (10000 yuan) & Exports of New Products \\
\hline
\end{tabular}

\section{THE COLLECTION OF ORIGINAL DATA AND THE SOLVING BY TOPSIS}

In order to effectively evaluate the overall effectiveness of the Liaoning equipment manufacturing industry technology upgrading, the paper selected some regions whose one or more indicators among scale of strength, innovation and competitiveness of equipment manufacturing in 2012 can be ranked in the top ten of the country as research subjects, and the regions respectively are Jiangsu, Shandong, Guangdong,
Zhejiang, Henan, Liaoning, Shanghai, Sichuan, Hubei, Anhui, Hebei, Heilongjiang, Shaanxi, Beijing, Yunnan, Shanxi, Tianjin. Other basic data come from China Statistical Yearbook of Science and Technology-2013and the data shows in Table 2.

The solving process of Topsis includes the following steps: (1) the original data is normalized, (2) the optimal solution $\mathrm{Z}^{+}$and the worst solution $\mathrm{Z}^{-}$are calculated, (3) the distance $\mathrm{D}^{+}$and $\mathrm{D}_{\mathrm{i}}^{-}$are respectively calculated between each evaluation object and $Z^{+}$and $Z^{-},(4)$ the proximity $C_{i}$ is calculated between each evaluation object and the optimal solution, (5) $\mathrm{Ci}$ sorted by size and the evaluation results is given [5]. Through the above steps, the results are shown in Table 3. It can be seen from Table $\mathbf{3}$, the proximity $\mathrm{C}$ is only 0.0961 between Liaoning and the optimal solutions, and is ranked twelfth among the 17 provinces. If the 17 provinces are ranked by the proximity $\mathrm{C}$, the first grade can be set as $\mathrm{C}>0.4$, second grade can be set as $0.1<\mathrm{C} \leq 0.4$, third grade can be set as $0.05<\mathrm{C} \leq 0.1$ and fourth grade can be set as $\mathrm{C} \leq 0.05$, then Liaoning equipment manufacturing industry is in the third grade and need to upgrade to the second or even the first grade.

\section{SENSITIVE ANALYSIS}

It is necessary for sensitivity analysis to first determine the changing range and distance of each indicator to conduct sensitivity analysis. In this case, the indicators selected are

Table 2. The original data of equipment manufacturing technology upgrading of 17 provinces in 2012. (unit, person, pierce, item, 10000 Yuan).

\begin{tabular}{|c|c|c|c|c|c|c|c|c|}
\hline Region & $\mathbf{X} 1$ & $\mathbf{X} 2$ & $\mathbf{X 3}$ & X4 & X5 & X6 & $\mathbf{X} 7$ & X8 \\
\hline Beijing & 75543 & 2191384 & 514032 & 747 & 33176311 & 14051 & 11024 & 5572510 \\
\hline Tianjin & 80972 & 2690406 & 977747 & 765 & 44601011 & 7341 & 12219 & 9317561 \\
\hline Hebei & 85498 & 2078549 & 904397 & 825 & 24576633 & 3358 & 7541 & 2926320 \\
\hline Shanxi & 44116 & 1662466 & 365134 & 177 & 9283912 & 2345 & 2726 & 1527286 \\
\hline Liaoning & 84369 & 2993886 & 878583 & 620 & 31936021 & 5054 & 8641 & 2257009 \\
\hline Heilongjiang & 48392 & 1008740 & 366270 & 278 & 5655068 & 2055 & 3384 & 541409 \\
\hline Shanghai & 108347 & 4100319 & 2509928 & 914 & 73999056 & 16805 & 17042 & 10544016 \\
\hline Jiangsu & 447951 & 11171433 & 7930442 & 16417 & 178454188 & 45120 & 53973 & 52727755 \\
\hline Zhejiang & 297465 & 6183654 & 3757439 & 7498 & 112839734 & 20553 & 41874 & 26744960 \\
\hline Anhui & 110739 & 2280702 & 1420360 & 2387 & 37318538 & 9215 & 15137 & 3137902 \\
\hline Shandong & 303862 & 9560978 & 4352300 & 3325 & 129131803 & 15104 & 28171 & 18640354 \\
\hline Henan & 140786 & 2609377 & 1033553 & 1414 & 25762027 & 5133 & 9106 & 2113763 \\
\hline Hubei & 112554 & 2719566 & 1386753 & 917 & 36984125 & 7025 & 9629 & 2368469 \\
\hline Guangdong & 519212 & 11255551 & 3066278 & 3455 & 154028478 & 83280 & 43314 & 59795805 \\
\hline Sichuan & 78406 & 1523738 & 1504854 & 879 & 20959773 & 6591 & 11656 & 1504602 \\
\hline Yunnan & 19116 & 422814 & 250335 & 287 & 4468160 & 1644 & 1512 & 262095 \\
\hline Shaanxi & 55794 & 1288451 & 646923 & 453 & 8715851 & 4752 & 6052 & 396375 \\
\hline
\end{tabular}


Table 3. The results solved by topsis of equipment manufacturing technology upgrading of 17 provinces in 2012.

\begin{tabular}{|c|c|c|c|c|c|c|c|c|c|c|c|}
\hline Beijing & 0.518 & 0.526 & 0.717 & 0.864 & 0.567 & 0.442 & 0.581 & 0.601 & 0.391 & 1.622 & 0.806 \\
\hline Hebei & 0.344 & 0.291 & 0.340 & 0.394 & 0.358 & 0.201 & 0.451 & 0.305 & 1.032 & 0.869 & 0.457 \\
\hline Shanxi & 0.351 & 0.450 & 0.393 & 0.175 & 0.410 & 0.148 & 0.303 & 0.213 & 1.189 & 0.807 & 0.404 \\
\hline Heilongjiang & 0.128 & 0.107 & 0.128 & 0.126 & 0.119 & 0.090 & 0.163 & 0.036 & 1.616 & 0.267 & 0.142 \\
\hline Shanghai & 0.094 & 0.127 & 0.088 & 0.040 & 0.142 & 0.072 & 0.132 & 0.106 & 1.661 & 0.245 & 0.129 \\
\hline Jiangsu & 0.130 & 0.128 & 0.125 & 0.048 & 0.117 & 0.069 & 0.104 & 0.027 & 1.677 & 0.213 & 0.113 \\
\hline Henan & 0.098 & 0.141 & 0.079 & 0.037 & 0.101 & 0.050 & 0.093 & 0.026 & 1.724 & 0.183 & 0.096 \\
\hline Hubei & 0.099 & 0.098 & 0.082 & 0.043 & 0.078 & 0.039 & 0.081 & 0.033 & 1.742 & 0.142 & 0.076 \\
\hline Guangdong & 0.065 & 0.061 & 0.059 & 0.024 & 0.028 & 0.047 & 0.065 & 0.005 & 1.803 & 0.0816 & 0.043 \\
\hline Sichuan & 0.051 & 0.078 & 0.033 & 0.009 & 0.030 & 0.023 & 0.029 & 0.017 & 1.835 & 0.065 & 0.034 \\
\hline Yunnan & 0.056 & 0.048 & 0.033 & 0.015 & 0.018 & 0.020 & 0.036 & 0.006 & 1.845 & 0.037 & 0.020 \\
\hline Shaanxi & 0.022 & 0.020 & 0.0226 & 0.015 & 0.014 & 0.016 & 0.016 & 0.003 & 1.876 & 0.006 & 0.003 \\
\hline$Z^{+}$ & 0.600 & 0.530 & 0.717 & 0.864 & 0.567 & 0.815 & 0.581 & 0.682 & & & \\
\hline
\end{tabular}

normalized data, changing range is select to be $-30 \%$ to $30 \%$ and the spacing is $5 \%$. The sensitivity analysis chart about Index rate of change and Proximity numerical is drawn as Fig. (1) by calculating. In Fig. (1), the slope of each line reflects the degree of sensitivity of corresponding to the index, the larger the slope is, and the stronger the sensitivity is. As the results shows by the illustration, among the eight indicators conducted sensitivity analysis, the sorting by the sensitivity from strong to weak in proper order is expenditure on R\&D, Sales Revenue of New Products, New Products, Equipment, Inventions In Force, institutions, exports of new product and R \& D personnel.

The stronger the sensitivity is, the greater the influence on the proximity $\mathrm{C}$ is. But to determine the real impact on the overall effectiveness of an index, it is necessary to to find a reference with which to compare. In this paper, the reference is chosen to be the higher grade, namely the second grade. Through data processing, the average growth rates of the proximity $\mathrm{C}$ of each indicator of Liaoning Province and five provinces in the second grade are obtained and the results are shown in Table 4. As can be seen from Table 4, only on the two indicators of R\&D expenditures and new product sales revenue, the average growth rate of the proximity $\mathrm{C}$ of Liaoning is bigger than the second grade's. The average growth rate represents the impact of indicators on the proximity $\mathrm{C}$, the greater the average growth rate is, and the greater the impact is. No matter compared with internal indicators or external same indicators, the impacts of R\&D expenditures and new product sales revenue of Liaoning Equipment Manufacturing on the proximity $\mathrm{C}$ are the greatest. Therefore, the conclusions can be drawn as following: the bottlenecks of Liaoning equipment manufacturing technology upgrading are R \& D expenditures and new product sales revenue.

\section{CAUSE AND COUNTERMEASURE FOR THE BREAKTHROUGH FOR BOTTLENECKS FORMA- TION}

\subsection{Analysis of the Cause for Bottleneck Formation}

Through quantitative analysis, this paper reach conclusion that the bottlenecks of Liaoning equipment manufacturing technology upgrading are R\&D expenditures and new product sales revenue. When Investigate the cause, as can be seen from Table 2, compared with the developed provinces, the R\&D expenditure of Liaoning is significantly lower, but the impact of R\&D expenditures of Liaoning on overall efficiency is the largest, so Inadequate R\&D expenditure results in lower ranking as a whole. In addition, it is understood that some companies of Liaoning Province set focus on the introduction of foreign complete set of products and services to access to higher economic efficiency in the short term, while 


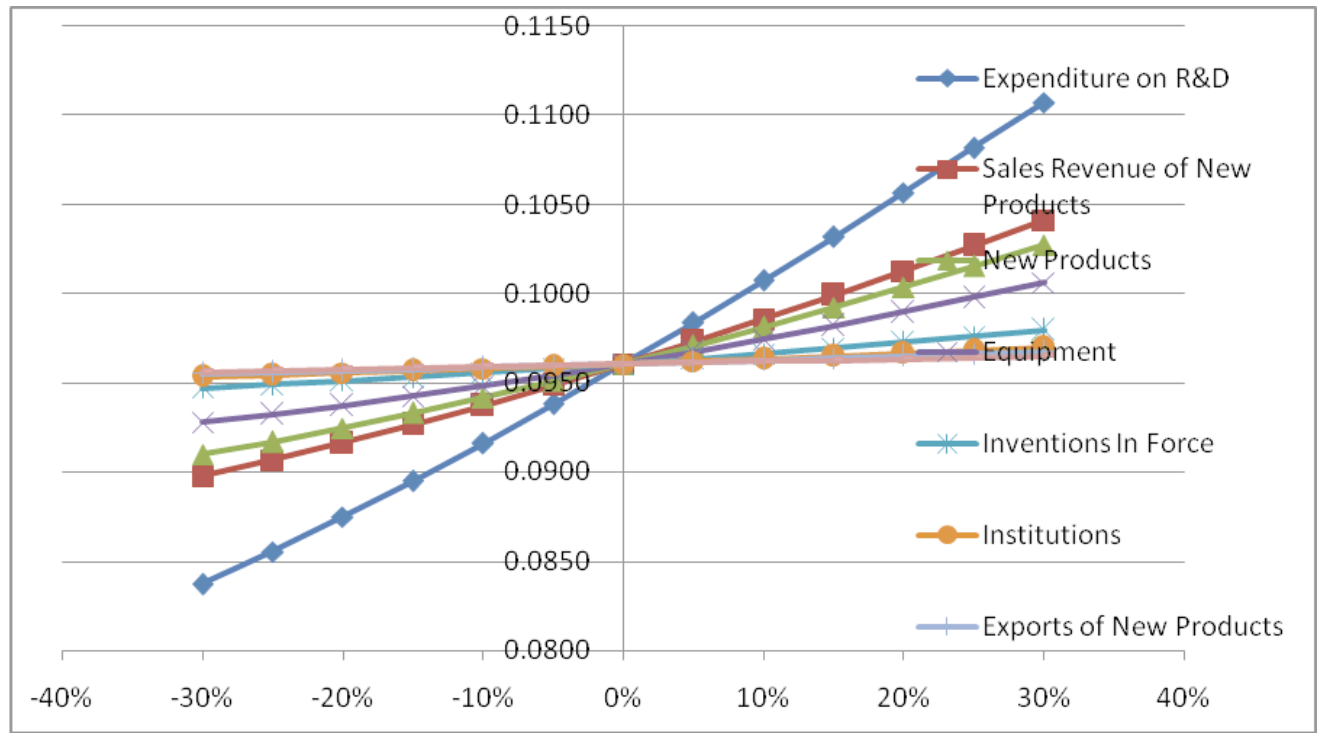

Fig. (1). Each index sensitivity analysis chart of Liaoning equipment manufacturing technology upgrading.

Table 4. The data table of average growth rate of Liaoning and other five provinces in the second grade.

\begin{tabular}{|c|c|c|c|c|c|c|c|}
\hline \multirow{2}{*}{ Indicators } & \multicolumn{7}{|c|}{ The Average Growth Rates of the Proximity C } \\
\cline { 2 - 8 } & Liaoning & Shanghai & Anhui & Tianjin & Hubei & Beijing & The 2nd Grade \\
\hline \hline & $0.07 \%$ & $0.10 \%$ & $0.10 \%$ & $0.07 \%$ & $0.09 \%$ & $0.07 \%$ & $0.09 \%$ \\
\hline X2 & $2.40 \%$ & $0.87 \%$ & $0.71 \%$ & $1.15 \%$ & $1.52 \%$ & $1.00 \%$ & $1.05 \%$ \\
\hline X3 & $0.78 \%$ & $1.22 \%$ & $1.03 \%$ & $0.58 \%$ & $1.47 \%$ & $0.19 \%$ & $0.90 \%$ \\
\hline X4 & $0.16 \%$ & $0.11 \%$ & $1.10 \%$ & $0.16 \%$ & $0.28 \%$ & $0.19 \%$ & $0.37 \%$ \\
\hline X6 & $1.36 \%$ & $1.26 \%$ & $0.91 \%$ & $1.48 \%$ & $1.35 \%$ & $1.10 \%$ & $1.22 \%$ \\
\hline X7 & $0.32 \%$ & $0.75 \%$ & $0.57 \%$ & $0.42 \%$ & $0.49 \%$ & $1.84 \%$ & $0.81 \%$ \\
\hline X8 & $1.13 \%$ & $0.82 \%$ & $1.61 \%$ & $1.28 \%$ & $1.05 \%$ & $1.36 \%$ & $1.22 \%$ \\
\hline
\end{tabular}

the introduction of technology digestion, absorption and reinnovation investment is less, and does not take shape of technological innovation system conducive to technology upgrading and new product development. It affects the ability to enhance business innovation, this will lead to lower technology content and added value and use value of new product, then this can't meet customer demand for sophisticated technology products, thereby this will affect new product sales.

\subsection{The Countermeasure for Breaking Through the Bot- tlenecks}

By the analysis of the cause for bottleneck formation, the crux of the bottleneck of technology upgrading is found out and that is the lack of technological innovation. Therefore, on one hand, the provincial government should increase efforts to support the equipment manufacturing enterprises, and provide a good environment and excellent platform to improve the innovation ability of equipment manufacturing enterprise through policy support and tax support measures, at the same time, encourage collaborative innovation to pro- mote enterprise transform from mastering assembly technology to mastering the core manufacturing technology. On the other hand, the equipment manufacturing enterprises should increase the investment in $\mathrm{R} \& \mathrm{D}$, increase digestion and absorption of foreign technology through establishing Enterprise Innovation Platform, and on the basis of independent research and development, conduct collaborative innovation with external innovation agency, and ultimately create highquality products and services to meet the need of times.

\section{CONCLUSION}

After the above analysis, we draw the following conclusions:

Liaoning equipment manufacturing industry is only in the national middle level in technology upgrading and there is a large gap between developed regions. In addition, its bottlenecks are $R \& D$ expenditures and new product sales revenue, the cause for bottleneck formation is less R\&D expenditure and lower technological content of weak sense of innovation and urgently need to take measures to improve it. This paper 
uses a single factor sensitivity analysis to study the impact of the evaluation on the results, but in reality many factors may also play a role, which may cause the results of this paper with some limitations.

\section{CONFLICT OF INTEREST}

The authors confirm that this article content has no conflict of interest.

\section{ACKNOWLEDGEMENTS}

This article is funded by: Liaoning province science and technology plan (Grant NO: 2012401028) and (Grant NO: 2013401028), project of Shenyang science and technology plan (NO: F12-276-5-09), Funded Project of liaoning province department of education (NO: w2013021) and (NO: w2013020).

\section{REFERENCES}

[1] H. Zou, J. Sun, and B. Xu, "On coupling mechanism of technical upgrade and science and technology innovation of equipment manufacturing industry in Liaoning Province," Shenyang University of Technology (Social Science Edition), vol. 6, no. 2, pp. 97$103,2013$.

[2] J. Si, The Regional Rank of Equipment Manufacturing: JIANGSU, Shandong and Guangdong Rank the Top Three, China Industry News, China, 2013.

[3] D. Geng, "The path selection of major manufacturing equipment technology Upgrading-based on the perspective of continuous innovation capability," Science \& Technology Progress and Policy, vol. 27 , no. 4, pp. 47-49, 2010

[4] Y. Qin, J. Lei, and M. Han, "The bottlenecks of equipment manufacturing industry localization and its solution," Economic Management, vol. 12, pp. 48-53, 2009.

[5] R. Shuming, "Market constraint on technology upgrading of equipment manufacturing industry by downstream enterprises' loss aversion," Studies in Science of Science, vol. 30, no. 3, pp. 387393, 2012.

(C) Hua et al.; Licensee Bentham Open.

This is an open access article licensed under the terms of the (https://creativecommons.org/licenses/by/4.0/legalcode), which permits unrestricted, noncommercial use, distribution and reproduction in any medium, provided the work is properly cited. 